\title{
Initial Experience Using the Palmaz Corinthian Stent for Right Ventricular Outflow Obstruction in Infants and Small Children
}

\author{
Daniel R. Turner, MD, Edwin Rodriguez-Cruz, MD, Robert D. Ross, MD, Thomas J. Forbes, ${ }^{*}$ MD
}

\begin{abstract}
The original Palmaz balloon expandable stent has been used extensively for the treatment of vascular stenoses in older children and young adults. Placement of the Palmaz stent in infants and small children, however, is limited by stent inflexibility, large delivery sheath size, and concerns about creating fixed obstructions after the placement of small diameter stents in growing patients. New Palmaz Corinthian stents were placed through 6 French sheaths in four high-risk patients with postoperative right ventricular outflow obstruction. Patients were not considered candidates for surgical repair. Median patient age and weight were 17 months (range 5-32 months) and $7.7 \mathrm{~kg}$ (range 4.6-11.1 kg), respectively. Median fluoroscopy time was $58.2 \mathrm{~min}$ (range 55.2-172 $\mathrm{min}$ ). No complications were encountered. In each case, successful stent placement was achieved, and surgery with cardiopulmonary bypass was avoided. Palmaz Corinthian stents are more flexible, require a smaller delivery sheath, have equal or increased radial strength, and can be maximally expanded to a greater cross sectional area when compared to the original Palmaz stent. These characteristics make the Palmaz Corinthian stent a reasonable alternative for use in a select group of infants and small children who are not candidates for surgical repair of postoperative right ventricular outflow obstruction. Cathet. Cardiovasc. Intervent. 51:444-449, 2000. $\odot 2000$ Wiley-Liss, Inc.
\end{abstract}

Key words: stents; heart defects, congenital; catheterization; stenosis; pediatrics

\section{INTRODUCTION}

Cardiologists have used balloon expandable intravascular stents since the late 1980s to treat atherosclerotic vascular stenoses in adults [1]. In 1991, stent technology was reported for the treatment of congenital and postoperative vascular stenoses in children [2]. Since that time, balloon expandable stents have been used successfully by pediatric cardiologists for the treatment of both right and left sided cardiac lesions.

The Palmaz balloon expandable stent (Johnson \& Johnson Interventional Systems, Sommerville, NJ) has been used extensively to treat congenital and postoperative right ventricular outflow obstructions in children and adults [3-8]. Although it is technically possible to place the original Palmaz stent in smaller patients [9], stent placement in this group is limited by stent inflexibility, large delivery sheath size, and the inability to dilate the smaller, shorter Palmaz stents to near adult vessel diameter.

The Palmaz Corinthian stent (Cordis Endovascular, Johnson and Johnson, Warren, NJ) is a recent addition to the interventional catheterization laboratory (Fig. 1). The stent is more flexible, may be delivered through smaller sheaths, and may be dilated to a greater maximal diameter when compared to the original Palmaz stent [10].
These characteristics make the Palmaz Corinthian stent attractive for use in infants and small children after carefully considering the risks and benefits of stent placement vs. surgery. This report describes our initial experience with the Palmaz Corinthian stent in a select group of infants and small children with postoperative right ventricular outflow obstruction.

\section{TECHNIQUE}

Stent placement was performed under general anesthesia. Standard percutaneous technique was used to access the femoral vessels or the internal jugular vein. Complete right and left heart catheterizations and angiograms were performed. The decision for stent placement was made after reviewing the case and angiograms with the pedi-

Division of Cardiology, Children's Hospital of Michigan, Department of Pediatrics, Wayne State University School of Medicine, Detroit, Michigan

*Correspondence to: Thomas J. Forbes, MD, Division of Cardiology, Children's Hospital of Michigan, 3901 Beaubien Blvd., Detroit, MI 48201-2196. E-mail: tforbes@dmc.org

Received 5 April 2000; Revision accepted 10 July 2000 

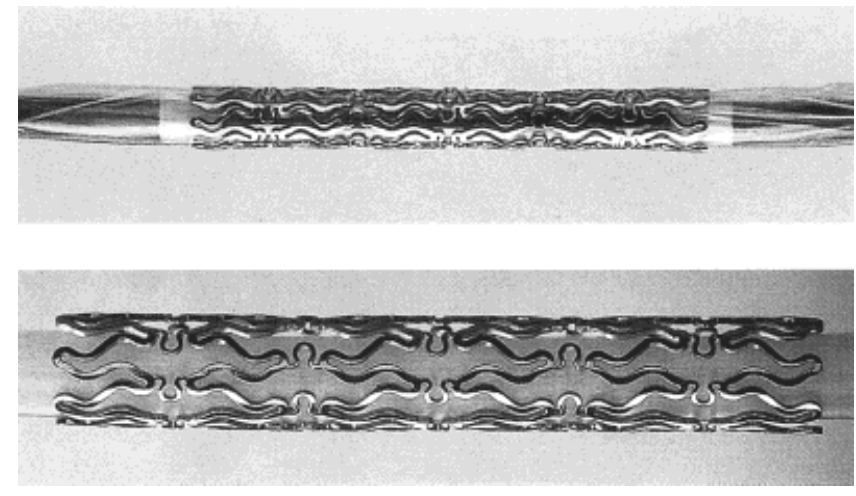

Fig. 1. The Palmaz Corinthian IQ stent, a new addition to the interventional catheterization laboratory. A new cell design and the addition of hinges connecting adjacent cells gives the stent improved pre-deployment flexibility, facilitating its delivery through tortuous anatomy.

atric cardiac surgeon to determine the risk and benefit of surgical vs. transcatheter management. Stent placement was selected if the patient was considered very high risk for surgery, or if surgery was undesirable due to multiple previous or anticipated surgical procedures. Predilation of the stenosis was necessary to facilitate placement of the delivery sheath. A $5 \mathrm{~mm} \times 2 \mathrm{~cm}$ Power Flex balloon catheter (Cordis Endovascular) was advanced over a 0.035 inch Rosen wire (Cook Corp., Bloomington, IN) and balloon dilation of the stenotic area(s) was performed. In Patients 1-3, a 6 French, $55 \mathrm{~cm}$ Brite-tipped sheath (Cordis Endovascular) was advanced over the angioplasty catheter and positioned across the stenotic area. In Patient 3, the Brite-tipped sheath kinked in the right ventricular outflow tract, making stent placement difficult. To decrease the likelihood of kinking, a 6 French, $45 \mathrm{~cm}$ Cook Flexor sheath (Cook Corp.) was used in Patient 4. In each case, an end-hole catheter was advanced through the delivery sheath over the 0.035 inch Rosen wire. The Rosen wire was exchanged for a 0.018 inch standard wire. The Palmaz Corinthian stents were loaded onto high pressure Jupiter 5-6 $\mathrm{mm} \times 2 \mathrm{~cm}$ balloon angioplasty catheters (Cordis Endovascular). The Jupiter balloon catheters tracked easily over the 0.018 inch wire and were maneuvered without difficulty through tightly curved delivery sheaths (Fig. 2). Stents were deployed using 12-14 atmospheres of pressure. Repeat hemodynamic measurements and angiograms were obtained after stent placement, however measurement of pressure gradient was not attempted if distal wire position was lost during catheter manipulation. Heparin was used during the procedure to keep the activated clotting time greater than $250 \mathrm{sec}$. Intravenous cefazolin was administered before stent deployment and for three additional doses. On the following day, a chest X-ray was

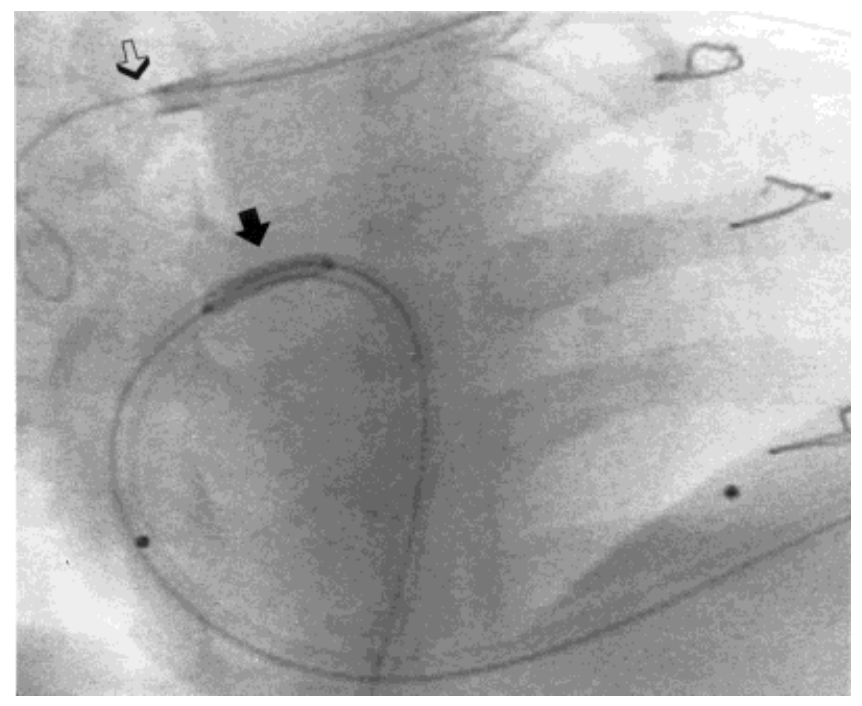

Fig. 2. Patient 2. A Palmaz Corinthian IQ stent mounted on a 6 $\mathrm{mm} \times 2 \mathrm{~cm}$ Jupiter balloon catheter (solid arrow) is seen within a 6 French delivery sheath. The tip of the sheath is in the proximal right pulmonary artery (open arrow). The balloon catheter tracks easily through the tightly curved delivery sheath, demonstrating enhanced pre-deployment stent flexibility.

obtained to document stent position, and aspirin was begun at $5 \mathrm{mg} / \mathrm{kg} / \mathrm{day}$.

\section{CASE SERIES}

\section{Results}

From November 1999 to March 2000, 5 Palmaz Corinthian stents were placed in 3 infants and 1 small child who were not considered candidates for surgery. Each stent was deployed in the desired position. Median patient age and weight were 17 months (range 5-32 months) and $7.7 \mathrm{~kg}$ (range $4.6-11.1 \mathrm{~kg}$ ), respectively. Hemodynamics are summarized in Table I. Median fluoroscopy time was $58.2 \mathrm{~min}$ (range 55.2-172 minutes). No complications were noted. Patient discharge occurred on the day after the procedure in three patients and four days after stent placement in one patient. Limited early follow-up is encouraging.

\section{Patient 1}

Patient 1 was born with pulmonary atresia, ventricular septal defect (VSD), and non-confluent pulmonary arteries supplied by a patent ductus arteriosus and collateral vessels. Due to complications of prematurity, he was maintained on prostaglandin infusion for an extended period. At 5 months of age, pulmonary artery unifocalization and placement of a $7 \mathrm{~mm}$ Dacron Hemashield valveless conduit from the right ventricle to the unifocalized pulmonary artery confluence was performed. The 
TABLE I. Hemodynamic Data

\begin{tabular}{|c|c|c|c|c|c|c|c|c|c|}
\hline \multirow[b]{2}{*}{ Patient } & \multirow[b]{2}{*}{ Diagnosis } & \multicolumn{2}{|c|}{$\mathrm{RVp}(\mathrm{mmHg})$} & \multicolumn{2}{|c|}{$\mathrm{RVp}: \mathrm{SBP}$} & \multicolumn{2}{|c|}{ Gradient $(\mathrm{mmHg})$} & \multicolumn{2}{|c|}{$\mathrm{SaO}_{2}(\%)$} \\
\hline & & pre & post & pre & post & pre & post & pre & post \\
\hline 1 & $\begin{array}{l}\text { PA, VSD, non- } \\
\text { confluent } \\
\text { pulmonary arteries, } \\
\text { proximal conduit } \\
\text { stenosis }\end{array}$ & 89 & 82 & 1.0 & 1.0 & 72 & 19 & 65 & 82 \\
\hline 2 & $\begin{array}{l}\text { PA, VSD, non- } \\
\text { confluent } \\
\text { pulmonary arteries, } \\
\text { proximal RPA/ } \\
\text { LPA stenosis }\end{array}$ & 78 & 81 & 1.0 & 1.0 & $\begin{array}{l}\text { RPA } 50 \\
\text { LPA } 55\end{array}$ & $\begin{array}{l}\text { RPA } 15 \\
\text { LPA } 37\end{array}$ & 58 & 88 \\
\hline 3 & $\begin{array}{l}\text { TOF, RV } \\
\text { hypertension, RV } \\
\text { failure, proximal } \\
\text { LPA stenosis }\end{array}$ & 95 & 68 & 1.1 & 0.8 & 67 & NA & 98 & 98 \\
\hline 4 & $\begin{array}{l}\text { TOF, RV } \\
\text { hypertension, } \\
\text { proximal LPA } \\
\text { stenosis }\end{array}$ & 68 & 51 & 0.9 & 0.6 & NA & NA & 99 & 98 \\
\hline
\end{tabular}

LPA, left pulmonary artery; PA, pulmonary atresia; RPA, right pulmonary artery; RV, right ventricular; $\mathrm{RVp}$, right ventricular pressure; $\mathrm{RVp}: \mathrm{SBP}$, right ventricle to systemic arterial blood pressure ratio; $\mathrm{SaO}_{2}$, pulse oximetry; TOF, tetralogy of Fallot; VSD, ventricular septal defect; NA, not available.

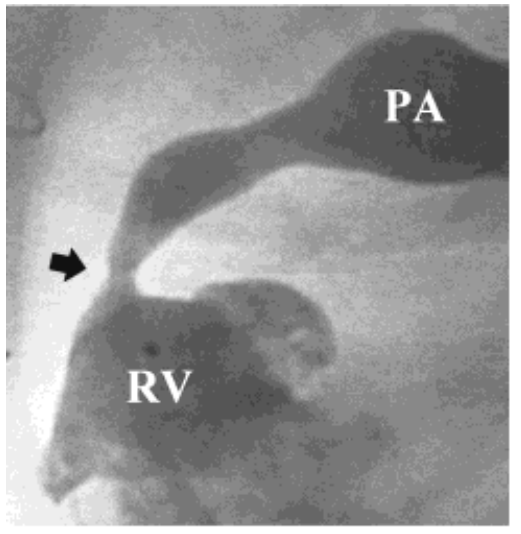

A

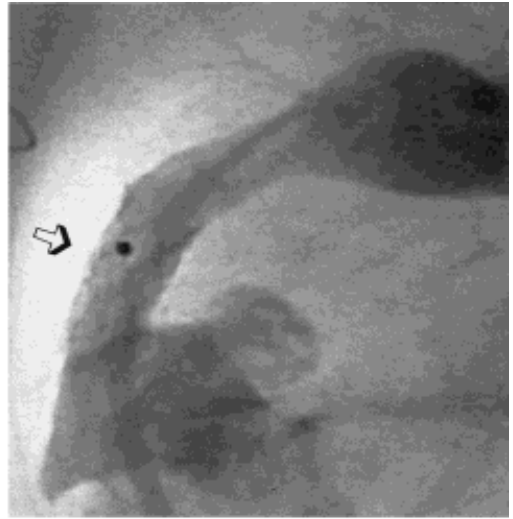

B
Fig. 3. Patient 1. (A) Lateral right ventriculogram showing severe proximal conduit stenosis (solid arrow). (B) Significant relief of the stenosis is seen after stent placement (open arrow). RV, right ventricle; PA, unifocalized pulmonary artery confluence. large VSD was left open, and right ventricular (RV) pressures remained systemic. Postoperative oxygen saturation was $82 \%$ in room air. Over the next 8 months, oxygen saturation slowly decreased to $60 \%$ secondary to progressive conduit and proximal left pulmonary artery (LPA) stenosis. Initial cardiac catheterization with balloon angioplasty of the conduit and LPA was acutely successful, however increasing cyanosis with echocardiographic evidence of conduit restenosis (proximal conduit diameter $1.9 \mathrm{~mm}$, estimated conduit gradient 70-75 $\mathrm{mm} \mathrm{Hg}$ ) prompted repeat catheterization 3 months later. Angiography confirmed severe proximal conduit stenosis (Fig. 3A), and stent placement was recommended to prolong the life span of the conduit. At 16 months of age and $8 \mathrm{~kg}$, a Palmaz Corinthian IQ 154 stent was placed in the stenotic proximal conduit with immediate relief of the stenosis (Fig. 3B) and improvement in systemic oxygen saturation from $65-82 \%$. Proximal conduit diameter increased from 2 to $5.5 \mathrm{~mm}(275 \%)$ and the conduit gradient decreased from 72 to $19 \mathrm{~mm} \mathrm{Hg}$ after stent placement. The RV pressures remained systemic pre- and post-stent placement due to the large VSD. Fluoroscopy time was $56.5 \mathrm{~min}$. There were no complications. The post-stent echocardiogram showed appropriate stent placement within the conduit, a total gradient of 20-25 $\mathrm{mm} \mathrm{Hg}$ across the RV outflow tract, and bi-directional shunting through the large VSD. The patient was discharged from the hospital on the day after the procedure.

At recent 5-month follow-up, oxygen saturation remained acceptable at $74 \%$. The conduit was patent by 


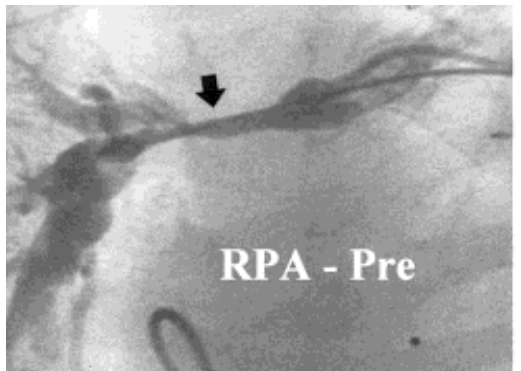

A

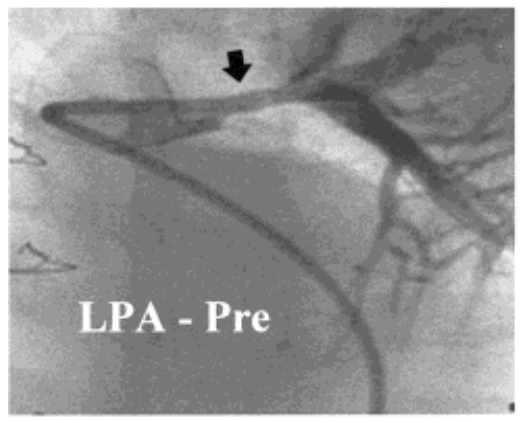

B

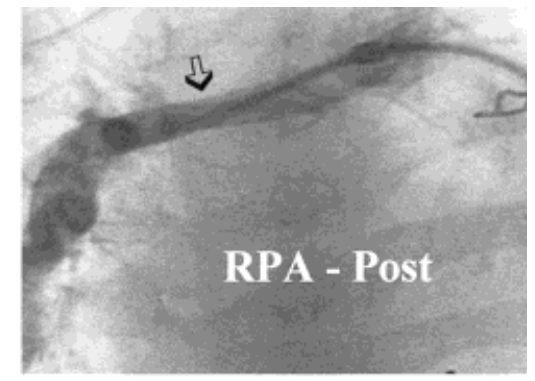

C

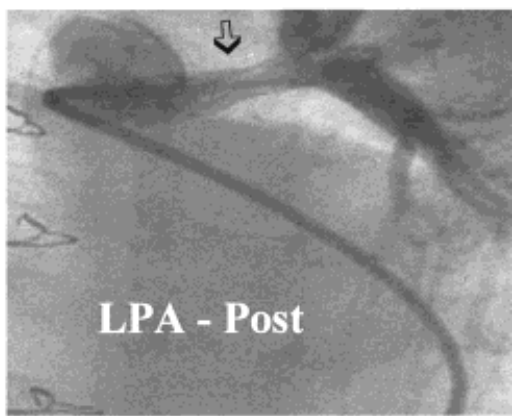

D
2-D echocardiography, however, accurate Doppler interrogation of the conduit was impossible due to conduit position in the chest.

\section{Patient 2}

Patient 2 presented at 9 months of age with pulmonary atresia, VSD, and non-confluent pulmonary arteries supplied by bilateral arterial ducts. At 11 months of age, pulmonary artery unifocalization, fenestrated $(5 \mathrm{~mm})$ closure of the VSD, and placement of a $13 \mathrm{~mm}$ aortic homograft from the RV to the unifocalized pulmonary artery confluence was performed. Postoperative RV pressures remained systemic due to the fenestrated VSD. Room air systemic oxygen saturation was $78 \%$ at hospital discharge. Due to progressive cyanosis, cardiac catheterization was performed at 15 month of age. Severe bilateral pulmonary artery stenosis was found and balloon angioplasty was performed with early success. Four months later, however, the patient presented with severe ascites, peripheral edema, and hypoxemia (systemic oxygen saturation 55-60\%). Echocardiography showed predominately right-to-left shunt through the VSD fenestration, a dilated RV with poor systolic function, and severe, bilateral proximal pulmonary artery stenosis. Cardiac catheterization confirmed severe right pulmonary artery (RPA) and LPA stenosis (Fig. 4A,B). At 18 months of age and $7.4 \mathrm{~kg}$, Palmaz Corinthian 185 and 155 stents were placed in the RPA and LPA, respectively, with acute relief of the stenoses (Fig. 4C,D), improvement in oxygen saturation to $88 \%$, and resolution of right ventricular failure. RPA diameter increased from 1.3 to $3.7 \mathrm{~mm}(285 \%)$ and LPA diameter increased from 1.9 to $3.7 \mathrm{~mm}(195 \%)$. Pressure gradients decreased from 50 to $15 \mathrm{~mm} \mathrm{Hg}$ across the RPA and from 55 to $37 \mathrm{~mm}$ $\mathrm{Hg}$ across the LPA. The RV pressures remained systemic pre- and post-stent placement due to the large VSD fenestration. Total fluoroscopy time was $172 \mathrm{~min}$ for the placement of both stents. There were no complications. Post-stent echocardiography showed normal RV systolic function and predominately left-to-right shunting through the VSD fenestration. The patient was discharged on the following day.

At 7 month follow-up, systemic saturation was $89 \%$ in room air and RV function was normal. Accurate Doppler gradients through the stents could not be obtained.

\section{Patient 3}

Patient 3 underwent complete repair of tetralogy of Fallot using a transannular patch and LPA angioplasty at 8 days of age after a persistent hypercyanotic spell. He was readmitted at 5 months of age after echocardiography showed progressive RV dysfunction with an estimated RV pressure of $85 \mathrm{~mm} \mathrm{Hg}$. Cardiac catheterization revealed severe LPA stenosis, a widely patent RPA, systemic RV and distal RPA pressures, and severely depressed RV function. At 5 months of age and $4.6 \mathrm{~kg}$, a Palmaz Corinthian IQ 154 stent was placed in the proximal LPA with acute relief of the stenosis. The proximal LPA diameter increased from 1.9 to $4.3 \mathrm{~mm}(210 \%)$. A $67 \mathrm{~mm} \mathrm{Hg}$ gradient was present across the LPA before 
stent placement, however, a post-stent gradient was not obtained due to loss of distal wire position. Systolic RV pressure was 95 (systemic pressure $85, \mathrm{RV}$ :systemic ratio 1.1) before and $68 \mathrm{~mm} \mathrm{Hg}$ (systemic pressure $82 \mathrm{~mm} \mathrm{Hg}$, ratio 0.8 ) after stent placement. RV end-diastolic pressure decreased from 23 to $13 \mathrm{~mm} \mathrm{Hg}$ after stent placement. Fluoroscopy time was $59.9 \mathrm{~min}$ and there were no complications. The post-stent echocardiogram showed appropriate stent placement and an estimated RV pressure of $55 \mathrm{~mm} \mathrm{Hg}$. The patient was discharged 4 days after the catheterization.

At 1 month follow-up, estimated RV pressure was again systemic $(90-95 \mathrm{~mm} \mathrm{Hg})$ with poor RV systolic function on the echocardiogram. Cardiac catheterization was performed, however the procedure was terminated due to respiratory difficulty and acute metabolic acidosis requiring intensive care management. No right heart pressures were recorded due to patient instability. Further evaluation revealed a pan-vasculitis that was treated with steroids. Most recent follow-up, 3 months after stent placement, showed an asymptomatic infant with significantly improved RV function despite persistently elevated RV pressures. Further hemodynamic evaluation is planned.

\section{Patient 4}

Patient 4 was born with tetralogy of Fallot and the left main coronary artery arising form the proximal right coronary artery. A modified Blalock-Taussig shunt was placed in infancy, and complete repair with placement of a $19 \mathrm{~mm} \mathrm{RV}$ to pulmonary artery homograft was performed at 22 months of age. Routine echocardiogram at 31 months of age showed a dilated RV, near systemic estimated RV pressures $(65-70 \mathrm{~mm} \mathrm{Hg}$ ), and diminished LPA blood flow. At 32 months of age and $11.1 \mathrm{~kg}$, cardiac catheterization showed near systemic RV pressures and a nearly isolated LPA on angiography. Distal LPA pressures could not be measured. A Palmaz Corinthian IQ 154 stent was placed in the nearly isolated, proximal LPA with immediate relief of the stenosis. Proximal LPA diameter was $4.8 \mathrm{~mm}$ after stent deployment and improved blood flow to the left lung was noted. No post-stent gradient across the proximal LPA was obtained due to loss of distal wire position. RV systolic pressure decreased from 68 (systemic pressure 78, ratio 0.9 ) to $51 \mathrm{~mm} \mathrm{Hg}$ (systemic pressure $80 \mathrm{~mm} \mathrm{Hg}$, ratio 0.6) after stent placement. Fluoroscopy time was 55.2 min and there were no complications. Post-stent echocardiography revealed good stent placement and an estimated RV pressure of $55 \mathrm{~mm} \mathrm{Hg}$. The patient was discharged on the day after the procedure.

\section{DISCUSSION}

Congenital or postoperative right ventricular (RV) outflow obstruction causes significant morbidity in children with heart disease. In patients with RV to pulmonary artery conduits, distal pulmonary artery obstruction exacerbates conduit valve insufficiency and causes RV volume overload. Postoperative conduit obstruction leads to RV pressure overload and ventricular dysfunction. These difficulties are successfully palliated in older children and adults with the use of balloon expandable stents [3-8].

As the complete surgical repair of various forms of congenital heart disease at a very young age becomes more common, postoperative right ventricular outflow obstruction in infants is encountered more frequently. Balloon angioplasty alone of peripheral pulmonary artery and conduit stenoses has only limited success [11-14], and surgical management is often required. In our series, balloon angioplasty achieved transient success $(<5$ months) in Patients 1 and 2, and was unsuccessful in Patients 3 and 4. Surgical management is, however, occasionally very high risk (Patients $1-3$ ) or undesirable due to multiple previous or anticipated surgical procedures (Patients 1 and 4). Stent placement, therefore, offers an attractive alternative to balloon angioplasty or surgery in this select group of patients.

Although balloon expandable stents have been used with some success in infants [9], limitations of the original Palmaz stent have prevented its widespread use in this age group. All sizes of the original Palmaz stent are inflexible, making them difficult to advance through a tightly curved delivery sheath. The Palmaz P128 and P188 stents are delivered through 9 French sheaths $(8$ French with front-loading) that are too large for infants. Although the Palmaz P154 stent may be delivered through a 6 French sheath, it is inflexible and tracks poorly over a wire, especially in infants and small children.

An ideal stent for use in infants would be flexible, deployable through a small sheath, and have radial strength similar to that of the original Palmaz stent. The Palmaz Corinthian stent, recently approved for use in adult hepatobiliary obstruction, has these characteristics. It is available as Palmaz Corinthian and Palmaz Corinthian IQ product lines. A new cell design and the addition of hinges to provide flex points between adjacent cells (Fig. 1) gives Palmaz Corinthian stents improved predeployment flexibility [10]. They can be delivered on high-pressure balloon catheters through 6 French sheaths in vivo, and most recently through a 5 French system in vitro. Radial strength is equal to (Palmaz Corinthian) or greater than (Palmaz Corinthian IQ) that of the original Palmaz P154 stent [10], an important characteristic for 
stents deployed in conduit and peripheral pulmonary artery stenoses.

An additional difficulty encountered with stent placement in infants and small children is that a relative stenosis of the stented vessel may occur as the patient grows, requiring future surgical intervention to relieve the stenosis. For this reason, stents that are not expandable to near adult vessel diameter are generally not used in infants at our institution. Stent placement is considered, however, when the patient's condition puts him or her at very high risk to undergo surgical correction with cardiopulmonary bypass, or when surgery is undesirable due to multiple previous or anticipated surgical procedures. In each of our patients, the cardiac surgeon believed the risk associated with surgical relief of RV outflow obstruction using cardiopulmonary bypass was too great, and for this reason stent placement was performed.

The original Palmaz P128 and P188 stents are expandable to adult vessel diameter, but require large delivery sheaths for deployment as previously discussed. The Palmaz P154 stent, deployable through a 6 French sheath, can be maximally expanded to $11 \mathrm{~mm}$ [10] to achieve a cross sectional area (CSA) of $0.95 \mathrm{~cm}^{2}$. The new design of the Palmaz Corinthian stents decreases stent foreshortening and allows for a greater final stent diameter at maximum expansion. The Palmaz Corinthian IQ 154 and 184 stents can be maximally expanded to 13 $\mathrm{mm}$ with a stent CSA of $1.33 \mathrm{~cm}^{2}$, a $40 \%$ increase in CSA compared to the Palmaz P154. Maximum expansion of Palmaz Corinthian stents is not, however, approved by the Federal Drug Administration.

In summary, our initial experience using Palmaz Corinthian stents in infants and small children with congenital heart disease is encouraging. The Palmaz Corinthian stent has superior flexibility, equal or improved radial strength, ease of delivery through a small sheath, and greater maximum expanded diameter and cross sectional area when compared to the original Palmaz stent. These characteristics make Palmaz Corinthian stents a reasonable alternative for use in a select group of infants and small children who are at high risk for surgical treatment of postoperative right ventricular outflow obstruction.

\section{REFERENCES}

1. Palmaz JC, Richter GM, Noeldge G, Schatz RA, Robinson PD, Gardiner GA, Becker GJ, McLear GK, Denny DF, Lammer J, Paolini RM, Rees CR, Alvarado R, Heiss HW, Root HD, Rogers W. Intraluminal stents in atherosclerotic iliac artery stenosis: preliminary report of a multicenter study. Radiology 1988;168: 727-731.

2. O'Laughlin MP, Perry SB, Lock JE, Mullins CE. Use of endovascular stents in congenital heart disease. Circulation 1991;83: 1923-1939.

3. Hosking MCK, Benson LN, Nakanishi T, Burrows PE, Williams WG, Freedom RM. Intravascular stent prosthesis for right ventricular outflow obstruction. J Am Coll Cardiol 1992;20: 373-380.

4. O’Laughlin MP, Slack MC, Grifka RG, Perry SB, Lock JE, Mullins CE. Implantation and intermediate-term follow-up of stents in congenital heart disease. Circulation 1993;88:605614.

5. Fogelman R, Nykanen D, Smallhorn JF, McCrindle BW, Freedom RM, Benson LN. Endovascular stents in the pulmonary circulation: clinical impact on management and medium-term follow-up. Circulation 1995;92:881-885.

6. Powell AJ, Lock JE, Keane JF, Perry SB. Prolongation of RV-PA conduit life span by percutaneous stent implantation. Circulation 1995;92:3282-3288

7. Shaffer KM, Mullins CE, Grifka RG, O'Laughlin MP, McMahon W, Ing FF, Nihill MR. Intravascular stents in congenital heart disease: short- and long-term results from a large single-center experience. J Am Coll Cardiol 1998;31:661-667.

8. Ovaert C, Caldarone CA, McCrindle BW, Nykanen D, Freedom RM, Coles JG, Williams WG, Benson LN. Endovascular stent implantation for the management of postoperative right ventricular outflow tract obstruction: clinical efficacy. J Thorac Cardiovasc Surg 1999;118:886-893.

9. Benson LN, Nykanen D, Freedom RM. Endovascular stents in congenital heart disease. Prog Cardiovasc Dis 1996;39:165-186.

10. Data on file, Cordis Endovascular, Johnson \& Johnson, Warren, NJ.

11. Rothman A, Perry SB, Keane JF, Lock JE. Early results and follow-up of balloon angioplasty for branch pulmonary artery stenosis. J Am Coll Cardiol 1990;15:1109-1117.

12. Lloyd TR, Marvin WJ, Mahoney LT, Lauer RM. Balloon dilation valvuloplasty of bioprosthetic valves in extracardiac conduits. Am Heart J 1987;114:268-274.

13. Zeevi B, Keane JF, Perry SB, Lock JE. Balloon dilation of postoperative right ventricular outflow obstruction. J Am Coll Cardiol 1989;14;401-408.

14. Ensing GJ, Hagler DJ, Seward JB, Julsrud PR, Mair DD. Caveats of balloon dilation of conduits and conduit valves. J Am Coll Cardiol 1989;14;397-400. 